\title{
Privatization, commodification and transformation in Japanese housing: ephemeral house - eternal home
}

\author{
Richard Ronald ${ }^{1,2}$ \\ ${ }^{1}$ OTB Research Institute for Housing, Urban and Mobility Studies, Delft University of Technology, the Netherlands \\ ${ }^{2}$ Department of Japanese and Korean Studies, Leiden University, the Netherlands
}

\author{
Keywords \\ Bounded space, commodification, home, \\ housing, Japan, privatization.

\section{Correspondence} \\ Richard Ronald, OTB Instituut, TU Delft, \\ Jaffalaan 9, 2628BX, Delft, the Netherlands. \\ E-mail: r.ronald@tudelft.nl
}

doi: $10.1111 / j .1470-6431.2009 .00803 . x$

\begin{abstract}
The space and place of the Japanese home holds an iconic status in both foreign and indigenous understandings of Japanese life. The architectural forms and bounded spaces of Japanese houses have historically been embedded in social practices that integrate individuals with hierarchical orders of space and social relations moving outwards from the house to community. Housing units and residential neighbourhoods have, however, undergone considerable transformation in the last century. Homes have been increasingly privatized, commodified and marketized, while the features of housing and neighbourhoods have been intensively modernized and urbanized. This paper considers transformations in the form of Japanese housing and the extent to which contemporary housing production and consumption mediates historically embedded notions of domestic relations and space.
\end{abstract}

\section{Introduction}

Houses are not simply shelters, but spaces that shape and are shaped by social interactions and cultural values. Japanese houses, in particular, have been identified as culturally distinct, and their inimitability bound up with parallel discourses, both within and without Japan, on the eternal Japanese family (Daniels, 2001; Ozaki and Lewis, 2006; Ronald, 2007). Despite such discourses, the physical spaces of homes, the organization of households and the shape of residential neighbourhoods have undergone continuous and radical transformation in Japan. The relationship between Japanese society and the built form of the home is more effectively addressed as a dynamic phenomenon, characterized by considerable reactivity to changing social conditions. This paper examines this process of transformation, which, while reflecting indigenous dwelling and construction practices, also illustrates processes of commodification and privatization of housing objects evident across developed societies. At the same time, unusual features of modern Japanese housing that perpetuate or recreate 'traditional' forms are also illustrated and their significance addressed.

This paper considers metamorphoses in the Japanese home from sociological and architectural perspectives. The first section highlights the relevance of the home in understanding social practices. The space and notion of 'house' has been understood in Japan to constitute a particular sociality and continuity, defining how family members relate to each other, which forms the basis of relationships beyond the place of home. The continuity of this conceptually 'eternal' house contrasts starkly with the 'ephemorality' of Japanese dwellings themselves as historically, houses have been built to be non-durable. The second part of the paper thus considers the shape and construction of built units, starting with pre-modern forms and accounting for transformations in dwellings through Japan's rapid urbanization and modernization. Contemporary vernacular housing is typically constructed from concrete and utilizes complex construction technologies, but nonetheless still features rush matting and paper screens that represent 'traditional' aesthetics and reproduce spatial boundaries evident in pre-modern housing. Moreover, while Japanese housing has been highly commodified and marketized, it continues to be consumed as a relatively disposable object, with built units being cyclically demolished and replaced. The final part of this paper considers, on one side, how Japanese homes have been transformed into modern housing goods, and on the other, how and why they retain indigenous features.

\section{The eternal home}

In the Anglo-American literature, homes and domestic spaces have been primarily discussed by architects, social historians and environmental psychologists. Qualitative research has been rare and interpretations of domestic spaces even rarer (Cieraad, 1999). Studies have been strongly rooted in the West and focused on the evolution of the separation between private and public spatial realms. The setting has been an occidental urbanism that can be traced back to 17th century Europe (Rybczynski, 1986). Houses in non-Western contexts have been treated in terms of exotic spaces, reinforcing the notion that industrialization and urbanization killed off 'residual popular symbolism' in the West (Cieraad, 1991). There is considerable evidence, nonetheless, that decoration and 
ritual associated with contemporary Western domestic spaces continue to play a central part in social and cultural relations (Miller, 1995).

Japanese domestic spaces have been typically treated as exotic in Western architectural appraisals (see Daniels, 2001), although indigenous architects and historians have also, on the whole, culturally essentialized the vernacular features of modern and pre-modern homes. ${ }^{1}$ However, contemporary Japanese houses demonstrate a similar orientation towards domestic privatism and divisions between private and public spaces. While spatial distinctions developed in terms of less familiar architectural boundaries, they represent parallel (re)negotiations in the meaning of space that has occurred in both reflective contrast to and isolation from Western housing practices. While housing has been increasingly commodified in terms of capitalist economy, domestic spatial transformations have been very different from those demonstrated in West European and North American homes. Essentially, this paper examines these developments in the industrially modernized non-occidental context of Japan, which both mirror and contrast to those found in Western countries.

Although houses are often taken to be rather mundane artefacts, dwellings give material shape to norms and constitute the main locus of association between individuals, households and the wider community. How the space of the house contains and structures household and family relationships reflect and reinforce cultural values. For Lawrence (1996), the space of the home and its boundaries come to regulate daily affairs and interactions, which for Bourdieu (1977) express and mediate social relationships that underpin the social system. Ozaki and Lewis (2006) thus argue that physical and spatial boundaries in the home are 'concrete manifestations of social classifications . . . internalized by people and experienced phenomenologically' (p. 91). Moreover, they emphasize that the order of space in Japanese houses is distinct from those in other societies and feature prominently in regulating social norms and cultural values. In Japanese, the word ie denotes the physical structure of the home as well as the family. Koyano (1996) emphasizes lineage in the conceptualization of ie, where contiguously succeeding generations define the family rather than the conjugal unit. The Japanese notion of house as a material space is thus bound to a more temporal and contiguous ideal of the household.

How boundaries in Japanese homes regulate the distinction between uchi and soto (literally, inside and outside) is particularly powerful in connecting physical spaces, cultural values and social practices. Fundamentally, outside places and categories are constituted as dangerous, impure and dirty and inside as safe, pure and clean (Ohnuki-Tierney, 1984). Individual identity and security are framed around, and maintained by, a strict regulation of inside and outside classifications. This involves identification with, and subjugation to, the authority of those inside one's uchi. Children become interdependent with and upon others within the (inside) group and fearful of making independent decisions that may lead

${ }^{1}$ The design, construction and layout of Japanese housing vary considerably by region and between different social classes. Arguably, 19th century farmhouses, or minka, are taken to be archetypal in Japanese architectural discourses on pre-modern housing. to expulsion. The word uchi is another signifier for one's home, with the house thus constituting the primary physical marker of $u c h i$ and soto distinctions.

The significance of the contrast between inside and outside is not specific to Japan. Indeed, the spatial demarcation of homes as private and separate from public space outside has long been central to discussions of domestic spaces in European societies [Van Gennep, (1909) 1981; Rosselin, 1999]. Moreover, the notion of public impurity that drove the specialization of hygienic tasks inside the home, considered the only place adequately safe and clean, is also strongly evident in Western contexts (Douglas, 1979). Nevertheless, anthropological analyses have forwarded the idea that the uchi-soto axis carries greater significance and constitutes a key polemic in Japanese culture around which children are socialized (Hendry, 1992).

In hegemonic Japanese discourses, houses embody the harmony and continuity of the family within, which connects to wider society without in terms of hierarchical extensions of the uchi boundary. Submission or loyalty to one's family is transferred to broader categories of $u c h i$ at regimented steps in the life course to include secondary groups made up of neighbours, schoolmates and colleagues, and ultimately fellow national subjects. Historically, this relationship between house, family and society has been emphasized in nationalistic discourses. Writing in the early 20th century, the cultural historian Watsuji pays special attention to the house: 'The concept of house in Japan takes on a unique and important significance as, if you like, the community of all communities ... The house marks the realm of inside and outside as unmistakably different. The house continues in Japan . . . not just as a formal entity but as a determinant of the Japanese way of life' [1988 (1935), p. 5]. While the home is considered a locus of identity in most societies, what is notable in the Japanese case is its explicit centrality in discourses on Japanese social sensibilities, both emotional and spatial.

Discussing Japanese houses in terms of $i e$ and uchi-soto provides a means to emphasize a cultural perception of space. It nonetheless errs towards a more exotic notion of a mythic space, far removed from the realities of modern housing. However, there are specific features evident in both pre-modern Japanese dwelling forms and contemporary vernacular housing. Characteristic are certain kinds of boundaries that create fundamental distinctions between spaces, as well as 'liminal' areas that allow transition between qualitatively different domestic regions. For Lawrence (1984), as unregulated movement through such boundaries can be a source of anxiety, clear spatial markers and rituals have been required to regulate the access of people and transfer of matter. Again, boundaries, markers and rituals that ease the transition from public to the private world are also evidenced in contemporary Western societies. The 'threshold' is a prime concept in anthropology and for Van Gennep [(1909) 1981] constitutes a zone de marge that separates and links two distinct territories. Nonetheless, the boundaries that shape transition into Japanese homes demonstrate a distinct and resilient hierarchy that is expressed architecturally.

\section{Boundaries, spaces and senses}

Typically, where space and wealth allow, Japanese family homes are contained within a plot of land surrounded by a wall. 
Transition between outside and inside is mediated, at one level, by gates constructed to reflect the status of the family inside. At the entrance to the house proper, inside the vestibule, is the agarikamachi, a sill fitted along the edge of the wooden floor, defining the step up, or transition into the home. For Nakagawa (2002), this is a special boundary that serves as $k e k k a i^{2}$ that connotes both the heterogeneity of the interior and exterior spaces and the relationship between them. Ritual and the organization of space around the entry also preserve the distinction between inside and out. For example, in the morning, gate and vestibule areas are swept and washed and before entering the home, shoes are removed and hands and face cleaned to ensure dirt is not transferred from the outside.

Within the home, distinctions between spaces are more nuanced. For Ashihara (1989), hierarchies of space in Japanese dwellings are created by different floorings and screens of varying translucency that mark boundaries by generating subtly different senses of space. These contrast with the use of solid walls and front-oriented symmetry of Western ${ }^{3}$ housing. Nakagawa defines Japanese domestic architecture in terms of these subtle spaces and boundaries, and how they are related:

Space in Japanese architecture is made up of transitory units, each unit serves, in essence, as a bridge between the fore-

ground and the deeper interior, and space consists of a series of such units, like the links of a chain ... It is endlessly fluid ... it is also true that the ever shifting 'boundary spaces' ... have given Japanese houses and Japanese culture their own unique style (2002, p. 1)

The three types of floor found in Japanese homes have separate lineages and signify different orders of space and use: earthen floors, wooden floorboards and tatami mats. Earthen floors areas (doma) found by the entrance of pre-modern houses often took up one-third of the interior and were made suitable for work activities by hardening with mortar. The necessity of social and economic exchanges between households and the community promoted by pre-modern modes of production required an intermediate space between public external and private household regions. The doma thus provided a point of contact between interior and exterior worlds. Although doma are rare in contemporary housing, the concrete surfaces of genkan (entrance vestibules) in Japanese homes are their remnants. They are liminal and signify the difference between, and transfer across, outside and inside. In modern homes the genkan marks a transition from private family space to the world at large and there remains a meaningful polarity between the clean sanctuary of the interior and the dirty world outside marked by rituals such as bowing and changing of footwear. While parallel rituals are also observed in Western entrance halls (Rosselin, 1999), exchanges are arguably more subtle and distinctions between spaces not so physically defined.

The construction of buildings with raised wooden flooring began with early storehouses, temples and elite dwellings. From the 12th century, wooden floors were incorporated into ordinary houses and become the stage of daily household routines as well as

\footnotetext{
${ }^{2} \mathrm{~A}$ marker fixing the bounds of a sacred place.

${ }^{3}$ 'Western' in this context is used to denote European and North American housing types, which are themselves heterogeneous and diverse. A more polemic ideal of 'Western' and indigenous styles has largely served as a point of contrast among Japanese architects.
}

ceremonial life. Before the 16th century, tatami mats were used sparingly and often only lined the edges of rooms, even in the homes of the well to do. Wall-to-wall tatami rooms later began to appear in domestic architecture along with other features associated with 'traditional' Japanese interiors including tokonoma recesses and sliding paper screens. Rooms where guests would be received and formal rituals carried out were laid in tatami. Over time the tatami mat became the fundamental unit of measure of Japanese floor plans, even in modern housing. Its dimensions of around $180 \times 90 \mathrm{~cm}(5 \mathrm{~cm}$ deep) can be combined in a single space in numerous ways that define different room types.

Instead of walled divisions between rooms, sliding and static partitions are used between regions of the home that provide more scope to emphasize or diminish separateness or continuity between adjoining areas. Reed blinds (yoshizu) and sliding screens (fusuma and shoji) constitute boundaries that establish a tone and regulate the level of connectedness between rooms and regions. This requires different types of shōji ${ }^{4}$ that vary in relative opaqueness. For Nakagawa (2002), shoji are intimately related to manners, aesthetics and the emotional climate of Japanese domestic life. For Watsuji however, they represent and maintain the harmony of the family, which contrasts sharply with the individualist orientation of Western architecture:

While the European house has thick walls and stout doors which is a construction stressing individuality and separation, the Japanese house has sliding doors which provide an element of division but only within the unity of mutual trust and not as the desire for separation. Just as there is no distinction between individual rooms in the house, where spaces cannot be locked apart, there is no distinction of the individual and society as a whole. Above all the physical house exhibits an internal fusion that admits no discrimination [1988 (1935), p. 4].

\section{The ephemeral house}

These 'traditional' features of Japanese housing had 'matured' by the late 19th century (Nakagawa, 2002), and continued to be reproduced into Japan's modern era. Houses were constructed from wood, and while the emphasis was on continuity of the household over generations, buildings themselves were put together rapidly and not expected to last more than a few decades. Indeed, the average life expectancy of Japanese dwellings is still between 25-40 years and is aligned with a practice of periodical demolition and replacement ('scrap and build'). This non-durable approach to housing, associated with cultural perceptions of transience and renewal, are considered integral to the aesthetic pattern of Japanese life (Hendry, 1995). For Hearn, writing in the late 19th century, when houses were often erected in a matter of days, Japanese dwellings reflect a particularly transient perception of the everyday objects in Japanese life: 'Generally speaking we build for endurance, the Japanese for impermanency. Few things for common use are made in Japan with a view to durability' (p. 16). This applied to the construction houses particularly, with 'the light shoji frames serving at once for windows and walls, and repapered twice a year; the matting renewed every autumn - all but

${ }^{4}$ Such as karakamishōji (opaque screens), sukashishōji (translucent screens) and itadoshōji (plank door screens). 
random examples of countless small things in daily life that illustrate the national contentment with impermanency' [Hearn, (1896) 2001, p. 17].

Practical concerns, such as the frequency of disasters like typhoons, earthquakes and fires, also promoted the construction of cheap wooden housing that is easily replaced. In terms of the commodification of Japanese housing, it has normatively established a perception of non-durability of construction materials and expectations that built units are transitory, requiring regular reconstruction. By the 1960s, nine out of 10 homes were still wooden constructions. Even with the advancement of concrete and steel in construction, by the 1990 s, wooden housing still made up $60 \%$ of stock while more than 300000 dwellings were demolished annually (BCJ, 2003). Research with contemporary homeowners has also demonstrated the persistence of perceptions of impermanence, even among residents of modern concrete apartment units (Ronald, 2008).

\section{Modernization in Japanese housing}

The evolution of pre-modern Japanese housing established perceptions and practices that remain apparent in modern construction. However, these disguise more radical transformations. A process of intensifying commodification has been evident, related to changes in families and their relationships to their homes, as well as changes in design and construction driven by urbanization, modernization and social change.

In Japan's Meiji period (1868-1912), industrial capitalists replaced feudal lords and class distinctions were formally abolished, with new social divisions emerging between working and middle classes. In 1873, the land tax system was revised and private ownership of land was recognized, with restrictions on buying and selling removed. Farmers no longer paid feudal tributes, but rather government taxes levied against land valuations, which forced many to sell up and seek work in the cities. This eroded attachments to ancestral places and the continuity of intergenerational relationships. Along with rapid industrialization and urbanization, the forces that had bound households to houses were broken down and remoulded. Two critical outcomes in the production and use of houses were, firstly, an increasing focus on family privacy, and secondly, a material elaboration of the home along with the growth of an urban middle-class.

Pre-Meiji households had broad and fluid compositions. The social and physical boundaries of the house had been more porous and often submerged in a network of intersecting relations within the community, while households themselves contained children and adopted children, parents-in-law, other in-laws, concubines, lodgers, servants and apprentices (Sand, 2003). In the late 19th century however, private family space and the design of houses emerged as nodes of intellectual concern. The Family Registry System (1871) and the Meiji Civil Code (1898) set in law a single model of the 'Japanese family system'. These measures embodied a particular notion of ie that bound the family to the home in fundamental ways. Although forms of domestic life were not new, the notion of the 'home' as an intimate space sequestered from society and centred on only parents and children was alien (Sand, 2003, p. 16).

The legal institutionalization and growing bourgeoisie concern with family life had an impact on the organization of the home, reordering hierarchies of space. Firstly, domestic life became increasingly focused around family gatherings. Previously, status differences separated family members, with meals, for example, taken on individual trays and eaten in order of household rank. In middle-class Meiji society however, modern values clashed with traditional ones. Gradually, eating around a common table and exchanging polite conversation became an ideal, and located in specified locations in the home. Secondly, new house designs facilitated greater privacy, although not individual privacy. A stronger ideology emerged around family land, which was typically enclosed by high fences, cutting the house off from its neighbours. Despite growing spatial pressures, Japanese domestic architecture continued to resist shared walls, which for Ozaki (2001) marked middle-class desires to establish a boundary of family privacy. Nonetheless, for turn-of-the-century urban working classes, tenements (nagaya row houses) and often slum conditions were the norm. ${ }^{5}$

In the late Meiji period, Japanese architects trained in Western techniques began to work on private commissions, especially the homes of the elite. Increasingly, house plans included Western features that came to signify sophistication and learning (Fujimori, 1993). Homes of the well to do, and later, the middle classes, began to integrate Western-style features. The incorporation of the Western and modern with the indigenous and traditional reflected two different ideals of home and family. Whereas the new ideal prioritized private family life and was associated with modern domestic ideas imported from the West, the other orbited a more eternal conception associated with lineage, heredity and the authority of the male head of household. In the course of the late 19th and early 20th centuries, these new and old ideals competed against each other. On the side of social modernization were groups of literati, influenced by Western forms and ideas. ${ }^{6}$ On the other side were conservatives and nationalists who considered industrialization and economic growth as means of nation building.

Developments in architecture, the growing focus on conjugal family privacy and the rapid pace of economic and urban growth increasingly normalized houses as consumable objects associated with middle-class status, lifestyles and values. The middle corridor house (nakaroka-shiki) became a standard type of middle-class urban housing in the interwar years. The internal corridor was important because it separated private, back stage spaces from public, front stage ones. The establishment of a family living room (chanoma) next to the drawing room where guests were received, at the (southern) front region of the house was significant as it would be located on the north, back stage region of earlier houses. Ozaki (2001) argues the relocation of the chanoma signified how embedded conjugal family values had become and how elevated private family space then was in the hierarchy of domestic regions. Types of living room-centred houses (ima-shiki) also became popular in which a single large central room was the focus of both family activities and receiving guests. Nonetheless, private bedrooms were rare and families continued to sleep together or separated only by removable paper walls. The idea of personal spaces

${ }^{5}$ Nagaya tenement housing still made up more than a third of city housing in 1907.

${ }^{6}$ Many reformers were Christians active in the katei movement, which sought to improve domestic hygiene, promote the ideal of the housewife and re-centre Japanese family life around child rearing. 
had to wait until the idea of personal privacy became common after the Second World War (Ozaki, 2001, p. 354).

\section{Post-war housing}

Following substantial war damage and a considerable housing shortage, new pillars of housing policy introduced in the $1950 \mathrm{~s}$ began to direct resources towards modernizing the housing system. They included the Government Housing Loan Corporation (1950), the Public Housing Act (1951) and the Japan Housing Corporation (JHC) (1950). Government policy effectively drove the expansion of the construction sector and a massive shift towards owner-occupied housing consumption. Although pre-war urban owner occupancy rates had been below 30\%, by the late 1950s most Japanese families were homeowners and housing construction was becoming Japan's leading industry.

While state motivations were largely economic and political (Hirayama and Ronald, 2007), housing reformers also sought to influence social behaviour by reshaping dwellings (Waswo, 2002). A notable innovation from the mid-1950s was JHCconstructed danchi: multi-family housing estates made up of concrete apartment structures. These promoted family lifestyles orientated around compact apartment units and included separate bedrooms and solid dividing walls following a new, more democratic logic that every household member should have a private individual space. Dining kitchens with table and chair arrangements also became standard features, distinguishing eating from sleeping areas. Layouts were standardized around an $\mathrm{N}+\mathrm{DK}$ formula, in which $\mathrm{N}$ denoted the number of rooms other than the dining kitchen (DK). The most typical layout was the $2 \mathrm{DK}$ (approximately $35 \mathrm{~m}^{2}$ ), deemed ideal for standard families, although 1DK for singles and 3-4DKs were produced for large families. NDK units also created demand for dinette sets, new electrical goods and labour-saving devices suited to modern residential units.

In the private sector, construction techniques and housing layouts followed those of the JHC. The mainstay product of the construction industry was initially ready-built detached housing. The dominant providers were small family businesses that also supplied custom-built dwellings for households with their own land, seeking to rebuild. As land became more expensive in the 1970s and 1980s, larger companies, who could take better advantage of factory-produced housing components and vertical and horizontal networks of subcontractors, advanced. Such companies could offer considerable variety in housing design, manufactured, delivered and erected on the customer's own land within a few months. By the 1990s, the number of homes being scrapped and rebuilt on-site using customized construction techniques accounted for $75 \%$ of new-build detached housing (Oizumi, 2007). By the 2000s, eight major housing companies dominated production, each providing a broad product range including up to 300 adaptable house designs, utilizing advanced prefabrication as well as concrete, steel and wood components.

Although scrap and build represents a cultural practice, embedded in the perceived non-durability of construction materials and cycles of housing renewal, its proliferation has been facilitated by the construction industry in context of post-war conditions. On one hand, perceptions of scarcity, strong private property rights and the security of employment during an era of rapid economic

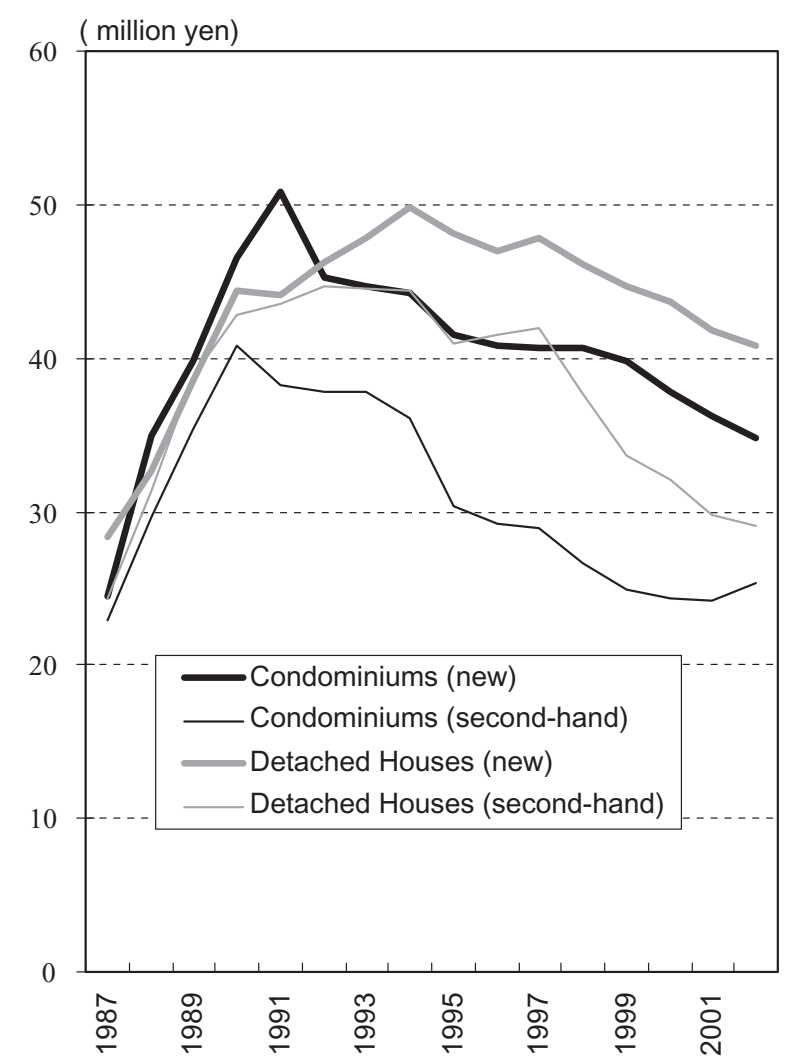

Figure 1 Housing value decline by type in Tokyo. Source: Hirayama (2007), Government Housing Loan Corporation (2002).

growth sustained an attachment to land as the focus of housing preferences. On the other, construction companies expanded and profited considerably from the high rate of construction. ${ }^{7}$ As in other countries, sharp and prolonged periods of house price increases accompanied by high rates of home ownership promoted the production and exchange of housing properties as market goods. The sharp economic downturn in the 1990s revealed key differences in Japanese housing construction and consumption practices. Speculative investment was a feature of housing markets in the 1970s and 1980s, with house prices driven by land price increases. Since land prices failed, the ephemorality of modern housing goods has become increasingly evident. As Japanese housing requires expensive maintenance and a cycle of rebuilding in order to maintain quality standards, housing units have functioned as consumption rather than investment goods. Since the 1990s, housing values have hung on the age and quality of the built unit, which declines rapidly: new-built houses are typically worth less than they cost to construct within 10-20 years and normally require to be completely rebuilt within 30 or 40 years. There has thus been a significant differentiation between types of housing, especially between new and old, detached houses and condominiums, in price declines (Fig. 1). In 2007, the '200-Year Home

${ }^{7}$ The rate of contemporary housing construction in Japan is 10-14 units per 1000 people, per annum compared with rates of 3-6 in Europe and the US. 
Figure 2 Housing units by stock type in Japan. Sources: Housing Survey of Japan (1973-1993) and Housing and Land Survey of Japan (2003).

Figure 3 Apartment buildings by number of floors in Japan. Sources: Housing Survey of Japan (1973-1993) and Housing and Land Survey of Japan (2003). ${ }^{*} 11+$ storey buildings constituted $4 \%$ of apartment buildings in 1978 and $7 \%$ in $1988 .{ }^{*} 6-10$ storey buildings made up $6 \%$ of apartment buildings in 1978.
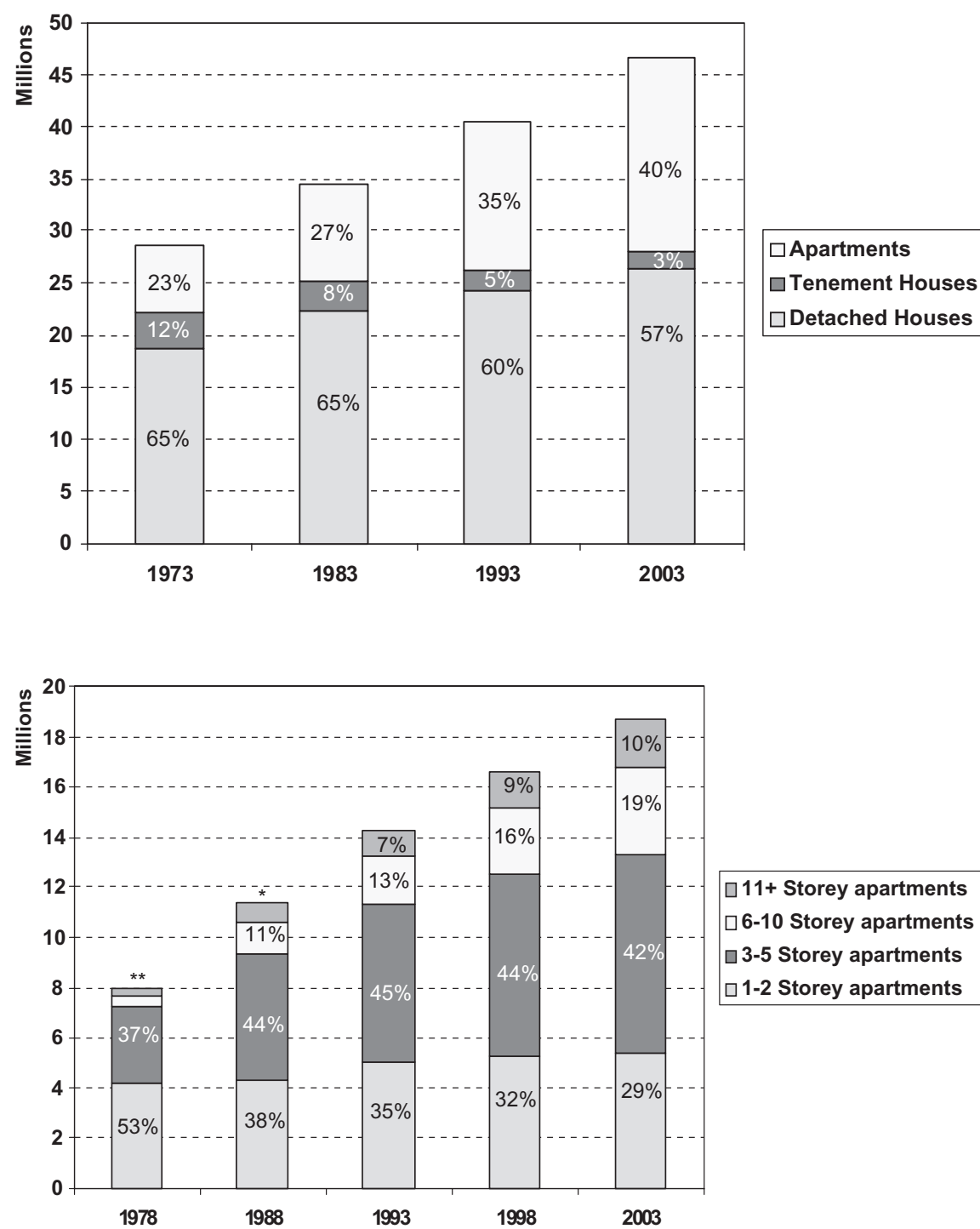

programme' was initiated by the government in order to promote the construction of more durable housing. So far, measures are limited and are unlikely to advance the average life span of Japanese dwellings considerably.

A trend of recent decades has been the decline in detached housing output in favour of condominium production. The first high-rise construction became possible after 1965 with the repeal of restrictions on building heights to 31 meters. As high-rise neighbourhoods then proved problematic to construct in established urban areas, mostly smaller scale private sector rental apartments, or manshon, were built. In the 1960s and 1970s, legislative changes made manshon condominium purchases viable for families who couldn't afford a house on its own land. In the 1970s, manshon output increased 10-fold in urban centres and values began to balloon. In the post-bubble 1990s, prices declined considerably especially for used condominiums. Production of new apartment dwellings, however, has advanced even more rapidly. Figs 2 and 3 illustrate the growing proportion of apartments and high-rise dwellings. A particular factor has been planning deregulation and intensified promotion of housing construction associated with 'urban renaissance' policies in the 1990s (Igarashi and Ogawa, 2003). The provision of tower condominiums in particular encouraged housing market hotspots and renewed desire for city centre living. Urban housing product has entered a new era characterized by taller apartment buildings and more compact urban dwellings.

In the future, two factors are likely to be central in the continued reshaping of homes and housing conditions. Firstly, the rate of renewal in the Japanese built environment continues to be exceptional. At the beginning of the 2000s, more than half of urban buildings were less than 20 years old. Secondly, there has been a notable decline in family formation with increases in smaller and older households. The ratio of single and couple-only households increased from $21.8 \%$ in 1970 to $49.1 \%$ in 2005 . With such a rapid rate of renewal in the built environment, urban and domestic landscapes are likely to adapt quickly to changes in families and lifestyles involving much more atomized and fragmented households and domestic spaces. 


\section{Discussion and conclusion: contemporary Japanese homes}

This paper set out to consider the material and meaningful transformation of Japanese houses and the extent to which contemporary homes perpetuate indigenous housing practices and social relations? There have been radical transformations illustrating considerable dynamism and reactivity in the built form of dwellings. A particular development has been an individualization and privatization of space. Nonetheless, an ideal of a more traditional collective sociality orientated around ' $i e$ ' has persisted in spite of social and spatial changes. Arguably, the focus on the eternality of the family, embodied in the conception of the family house, has provided a sense of continuity through a period of considerable change in household relations, radical social and economic modernization and transformation in the material landscape of communities and homes (Ronald, 2007).

The integration of the family ideal with its physical locale, the home, is not unusual to Japan. Neither is the privatization of family space. However, for Ozaki (2001) , modern Japanese housing designs reflect a 'family centeredness' and 'family privacy' in contrast to 'home centeredness' and 'individual privacy' in western housing. It could be further suggested that physical features of contemporary houses that demark a 'traditional' organization of space constitute a spatial discourse on the continuity of the family and cultural relations that transcend the existing household.

There are a number of continuities in Japanese homes, notwithstanding transformations in form, which appear to maintain or reflect an indigenous spatial discourse. The most obvious is the genkan entrance vestibule that marks a liminal zone of transition between the heterogeneous realms of inside and outside. Boundaries are also evident in cleaning areas. Modern Japanese houses typically have separate toilets and bathrooms with further subdivisions between body washing and bathing areas that facilitate the transfer of bodies and matter and prevent contamination. Washing machines are found either in a zone of the bathroom or veranda and never the kitchen. The purity of different rooms in the house are thus still maintained through boundaries and rituals, with entering and leaving different zones requiring putting on and taking off of different footwear.

Another feature consistent with pre-modern houses is the enclosure of properties with walls and fences. For Ozaki and Lewis (2006) physical isolation is related to family senses of intimacy and safety, and although similar barriers that resist the proximity of neighbours are also observed in western societies, the aversion to physical contact between household spaces in Japan is extreme. Families not only erect high fences but also go to lengths to prevent contact between the walls of adjoining properties. The result is the creation of very inefficient voids between detached properties.

A notable continuity in Japanese interiors is the persistence of Japanese-style rooms ${ }^{8}$ with accompanying tatami mats and shōji screens. Nakagawa (2002) identifies that in the modern period, the family room, chanoma, and the space reserved for formally entertaining guests, zashiki, became combined to constitute a

${ }^{8} \mathrm{Known}$ as washitsu in Japanese with Western-style rooms designated as yōshitsu. ribingu ruumu (living room). Traditionally separated functions were therefore mixed together in confusion (p. 118). The perpetuation of at least one Japanese-style room in the typical home arguably reflects the need for a space that, while conveying the informal family-centred atmosphere of a chanoma, can also function as a zashiki. Furthermore, tatami matting and removable sliding screens are more adaptable to a complex mix of overlapping functions. For Daniels (2001) however, washitsu play a more meaningful function. While Japanese houses are normally pre-fabricated consumer objects and households increasingly fragmented, an ideology of the harmonious family has been perpetuated by touches of domestic tradition. For Moeran and Skov (1997), there are two overlapping rhythms of consumption in Japan: the quicker driven by fast-changing fashion and the slower reflecting a consumption of tradition. For Daniels (2001), the Japanese house embodies both ideals through its mix of modern and traditional elements, which are reinvented and posed against each other.

Analyses of advanced capitalist societies have emphasized the continued growth of commodity relations and their increasing penetration into all aspects of social life (Giddens, 1991). Housing has been central to commodification processes, firstly, through the intensified marketization of residential properties, and secondly, as dwellings have increasingly become a forum of lifestyle consumption. Nonetheless, housing commodification in Japan demonstrates unusual features in these terms. Firstly, Japanese housing objects have retained many pre-modern domestic features and operate rather unconventionally as market commodities. Secondly, housing consumption practices have been bound up with ideologies of the family. This is not unusual, but has a particular salience in this context. While Japan has demonstrated an orientation towards intensive consumption and consumer-orientated identification practices, Clammer (1995) suggests caution in applying Western categories as Japanese modernity is characterized by: tradition as a way of handling change, group orientation coexisting with many varied if subdued forms of individualism and a strong emphasis on fate and desire for continuity (p. 57). Japanese houses, and their strong association with an iconic family and traditional community life, have therefore provided greater scope for the reproduction and consumption of cultural ideals. Arguably, contemporary housing combines the consumption of modern lifestyle goods, on one side, and a mythical notion of an eternal Japanese family and community, on the other.

\section{References}

Ashihara, Y. (1989) The Hidden Order: Tokyo Through the 20th Century. Kodansha International, Tokyo.

BCJ (2003) Building Centre of Japan: A Quick Look at Housing in Japan. BCJ, Tokyo.

Bourdieu, P. (1977) Outline of a Theory of Practice. Cambridge University Press, Cambridge.

Cieraad, I. (1991) Traditional folk and industrial masses. In Alterity, Identity, Image: Selves and Others in Society and Scholarship (ed. by R. Corbey \& J.T. Leersen), pp. 17-36. Editions Rodopi, Atlanta, GA. Cieraad, I. (ed.) (1999) At Home: An Anthropology of Domestic Space. Syracuse University Press, New York.

Clammer, J. (1995) Difference and Modernity: Social Theory and Contemporary Japanese Society. Kegan Paul International, London. 
Daniels, I.M. (2001) The untidy Japanese house. In Home Possessions: Material Culture Behind Closed Doors (ed. by D. Miller), pp. 201229. Berg, Oxford.

Douglas, M. (1979) Purity and Danger: An Analysis of Concepts of Pollution and Taboo. Routledge and Kegan Paul, London.

Fujimori, T. (1993) Nihon no Kindai Kenchiku [Japan's Modern Architecture]. Iwanami Shouten, Tokyo.

Giddens, A. (1991) Modernity and Self Identity: Self and Society in the Late Modern Age. Stanford University Press, Stanford, CA.

Hearn, L. [(1896) 2001] Kokoro: Hints and Echoes of Japanese Inner Life. Houghton Mifflin Company, Boston. Repr. ICG Muse, Tokyo.

Hendry, J. (1992) Individualism and individuality: entry into a social world. In Ideology and Practice in Modern Japan (ed. by R. Goodman \& K. Refsing), pp. 55-70. Routledge, London.

Hendry, J. (1995) Understanding Japanese Society. Routlege, London. Hirayama, Y. (2007) Reshaping the housing system: home ownship as a catalyst for social transformation. In Housing and Social Transition in Japan (ed. Y. Hirayama \& R. Ronald), pp. 15-46. Routledge, London. Hirayama, Y. \& Ronald, R. (eds) (2007) Housing and Social Transition in Japan. Routledge, London.

Igarashi, Y. \& Ogawa, A. (2003) Toshi Saisei wo Tou [Denouncing [Urban Renaissance']. Iwanami Syoten, Tokyo.

Koyano, W. (1996) Filial piety and intergenerational solidarity in Japan. Australian Journal on Ageing, 15, 51-56.

Lawrence, R.J. (1984) Transition spaces and dwelling design. Journal of Architectural Planning and Research, 1, 261-271.

Lawrence, R.J. (1996) The multidimensional nature of boundaries: an integrative historical perspective. In Setting Boundaries: The Anthropology of Social and Spatia Organisation (ed. D. Pellow), pp. 9-36. Bergin and Garvey, Westport, CT.

Miller, D. (1995) Acknowledging Consumption. Routledge, London.

Moeran, B. \& Skov, L. (1997) Mount Fuji and the cherry blossoms: a view from afar. In Japanese Images of Nature (ed. by P. Asquith \& A. Kalland). Curzon Press, Richmond, Surrey.
Nakagawa, T. (2002) Nihon no Ie: kukan, Kioku, Kotoba [The Japanese House: in Space, Memory and Language]. TOTO Shuppan, Tokyo.

Ohnuki-Tierney, E. (1984) Illness and Culture in Contemporary Japan: An Anthropological View. Cambridge University Press, Cambridge.

Oizumi, E. (2007) Transformation in housing construction and finance. In Housing and Social Transition in Japan (ed. Y. Hirayama \& R. Ronald), pp. 47-72. Routledge, London.

Ozaki, R. (2001) Society and housing form: home centredness in England vs. family centeredness in Japan. Journal of Historical Sociology, 14, 337-357.

Ozaki, R. and Lewis, J.R. (2006) Boundaries and the meaning of social space: a study of Japanese house plans. Environment and Planning D: Society and Space, 24, 91-104.

Ronald, R. (2007) The Japanese home in transition: housing, consumption and modernisation. In Housing and Social Transition in Japan (ed. by Y. Hirayama \& R. Ronald), pp. 165-192. Routledge, London.

Ronald, R. (2008) Between investment, asset and use consumption: the meaning of home ownership in Japan. Housing Studies, 23, 233-251.

Rosselin, C. (1999) The ins and outs of the hall. In At Home: An Anthropology of Domestic Space (ed. by I. Cieraad), pp. 53-59. Syracuse University Press, New York.

Rybczynski, W. (1986) Home: A Short History of an Idea. Heinemann, London.

Sand, J. (2003) House and Home in Modern Japan: Architecture, Domestic Space and Bourgeois culture, 1880-1930. Harvard University Press, Cambridge.

Van Gennep, A. [(1909) 1981] Les Rites de Passage. Editions Picard, Paris.

Waswo, A. (2002) Housing in Post-war Japan: A Social History. Curzon Press, Surrey.

Watsuji, T. (1988) The family as an ethical system (originally published in 1935). In Inside the Japanese System: Readings on Contemporary Society and Political Economy (ed. by I. Okimoto \& T.P. Rohlen), pp. 3-6. Stanford University Press, Stanford, CA. 